\title{
Van tuin naar terras - een etymologische wandeling door Europa
}

\section{From Garden to Terrace - A Journey Along the Origin of Words}

\author{
Jos Wilmots
}

\begin{abstract}
An answer to the question how different languages have handled form and meaning of concepts that in Dutch vocabulary became tuin, gaard, haag, park, laan, dreef, terras. We start in the Dutch tuin [garden] inside a fence, German Zaun being the fence itself and English town, which is a whole city. Dutch gaard has a lot of relatives in European languages. After a walk through hagen [hedges], lanen [lanes], dreven [alleys] all over Europe, we land in Amsterdam "op een terrasje van het Leidse plein ..." [on a terrace at Leiden square ...].
\end{abstract}

\section{Keywords}

etymology, garden, terrace, square, park, lane 


\section{De herkomst van woorden tuin, gaard, haag, park, laan, dreef en terras}

Dat onze straten Latijnse geplaveide wegen zijn (van het werkwoord sternere / stravi / stratum), weten we nog wel. Maar ook de herkomst van bv. tuin en terras verraadt de verwantschap binnen de Indo-Europese taalfamilie. En bij dat tweetal hoort nog een aantal andere, semantisch al dan niet verwante woorden :

1. tuin; 2. gaard; 3. haag / heg / hek - muur - wal - wand;

4. park ; 5. laan - avenue; 6. dreef; 7. terras

\section{1. tuin :}

- Nl.tuin : binnen de omheining

- Dt. Zaun : de omheining zelf

- E. town : een hele (ommuurde) stad > London

- als tweede deel ook van Gallo-Romeinse stedenamen :

Verdun $<$ Virodūnum

Onze Nederlandse tuin kan een bloementuin, een groententuin, enz. zijn. Over die bloementuin staat in mijn Taalknutselboekje van 2005 onder de titel

\section{Toewijding :}

\section{Mijn buurman is een bloemoloog; \\ hij laat zijn tuin floreren: één flambayantge regenboog van bloemen, God ter ere. \\ Hij zaait, pikeert, verpot en wiedt, herschikt, strooit roze korrel; sproeit in de schaduw en begiet zichzelf dan met een borrel.}

Maar veel bekender zijn natuurlijk de Japanse Tuin in Hasselt, de grootste van Europa, en de Tuinen van Hoegaarden bv. En die brengen ons bij gaard, zoals in de naam van het Zuid-Limburgse kloosterkasteel Mariagaarde en de gewone boomgaard (die tegenwoordig veelal fruitplantage heet). Al moeten we oppassen met Hoegaarden: daar zit etymologisch helemaal geen gaard in, het heeft van doen met een Germaanse persoonsnaam Hugward, waarvan het hier cursieve deel "hoeder" betekende.

\section{2. gaard:}

- Nederlands

(boom)gaard

- Duits

Garten

- Engels

(Scotland) Yard

- Tsjechisch 
- Oud-Pools

- Pools

- Russisch

- Servisch

- Hongaars

- Fins

- Latijn

- Frans

- Spaans

- Portugees

- Italiaans gród

gród warowny

Novgorod

Beograd

Visigrad

kartano

hortus

jardin

jardin (de flores) / huerta (moestuin)

jardim

giardino stad

burcht

nieuwe stad

witte stad

hoge vesting

kasteelboerderij

Dat tuin en gaard naar de betekenis (semantisch) verwant zijn, is duidelijk. Beide begrippen wijzen ook in al die andere talen op een omsloten / omheind stuk grond, een aan alle kanten omringd gebied. Het is dan ook niet verwonderlijk dat de Duitse Garten bij ons de tuin is en de Engelse town een stad. Onze gaard wordt in Slavische talen dan weer stad of burcht / hoge vesting, zoals in de naam van verscheidene steden in Middenen Oost-Europa :

- Vyšehrad : een oud vestingstadje in Tsjechië

- Višegrad / Вишеград : stadje in het oosten van de Servische Republiek in Bosnië en Herzegovina.

- Vishegrad : een dorpje in het zuiden van Bulgarije

- Visegrád : stadje met een ruïne van een koninklijk paleis in Hongarije

Dat onze gordel en het werkwoord omgorden met gaard verwant zijn, zal evenmin verwonderen. Deze begrippen leiden als vanzelf naar een derde groep van woorden, die met omsluiten van doen hebben :

\section{3. heg / haag / hek - muur / wand}

- heg: (om)heining van geschoren struiken

- haag : ook struikgewas / laag bosje cfr. 's Gravenhage / Den Haag

- hek : van latten of metaal - dranghekken (mv.)

- muur < lat. murus : oorspronkelijk stadsmuur - met stenen gemetseld (cfr. de beroemde Klaagmuur in Jeruzalem)

- $\quad$ wal < lat. vallus : aarden ophoging

- $\quad$ wand < ww. Winden - oorspronkelijk gevlochten twijgen / takken

En wie aan het begrip beperken / inperken denkt, komt als vanzelf bij een volgende groep van woorden uit : 


\section{4. park :}

- park < fr. parc / eng. park (omheining / lusthof)

- perk : direct $<$ lat. parricus (omheind terrein)

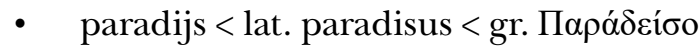

$<$ een Oost-Iraanse taal : omwalling

- daaruit ook Hebreeuws pardēz (tuin)

Hier denken we aan Hyde Park in Londen, de Jardin du Luxembourg in Parijs, die wel meer is dan een tuin, de parken rond het Casino van Monte Carlo, rond de Vlaamse kastelen van Gaasbeek in Vlaams Brabant of Ooidonk in Oost-Vlaanderen, de kasteeltuin van Arcen in Nederlands Zuid-Limburg.

Om bij of in zo'n park te komen moet men vaak door een

\section{5. laan :}

- laan : oorspronkelijk allicht een (veld)weg waarlangs het vee liep / toegang had / gedreven werd - nu veelal geassocieerd met bomen links en rechts

- cfr. eng. lane

- fr. equivalent allée $<$ ww. aller / gaan - toegangsweg $>$ Duits : die Allee

- fr. avenue < ww. avenir / aankomen > Engels : Fifth Avenue

- fr. boulevard < nl. bolwerk : met hout versterkt verdedigingswerk / vesting > ringweg (op de vroegere stadswal)

De "boelvaar" van Hasselt bestaat uit lanen. In de nieuwere wijken van de stad (vanaf de Tweede Wereldoorlog) zijn er haast geen straten meer. Eerst was er de Casterwijk, met Vuurkruisenlaan / Oudstrijderslaan / Elf Novemberlaan / Bondgenotenlaan allemaal vaderlandslievende begrippen. In de latere Catharinawijk werden de lanen naar Vlaamse humanisten genoemd: Andreas Vesaliuslaan / Justus Lipsiuslaan / Gerard Mercatorlaan / Rembert Dodoenslaan ... of naar iets jongere wetenschappes uit de Nederlanden: Jan van Helmontlaan / Jan Palfijnlaan . Op Henegauwberg werden het Kloosterlaan / Priorijlaan / Sepulkrijnenlaan / Kasteellaan. Als we het gebruik van laan en straat vergelijken, blijkt het eerste woord meer prestige te hebben, wat zelfs aanleiding kan geven tot een wat ironische interpretatie :

$$
\begin{aligned}
& \text { laan }><\text { straat } \\
& \text { Oudstrijderslaan }><\text { Weggevoerdenstraat } \\
& \text { Weerstandslaan }><\text { Congostraat } \\
& \text { Elf-Novemberlaan }><\text { Elfde-Liniestraat } \\
& \text { (wapenstilstand } 1918 \text { - naam van het regiment } \\
& \text { officiële feestdag de beklagenswaardige soldaten) } \\
& \text { laan }><\text { straat } \\
& \text { Berkenlaan }><\text { Beukenstraat } \\
& \text { Hazelarenlaan }><\text { Boomkensstraat } \\
& \text { Universiteitslaan }><\text { Schoolstraat }
\end{aligned}
$$


De namen van de rechterkolom vinden we in de Hasseltse volkswijk Runkst.

Bij het begrip laan zijn we weliswaar geneigd aan bomen links en rechts te denken. Maar het kan ook gewoon om (relatief jonge) straten (in recente wijken) gaan, zoals in het grote Amsterdam: boven en rond een Laan van Spartaan liggen daar heel sportief bij elkaar de :

- Wim van Estlaan (in de jaren vijftig van de vorige eeuw een van de eerste Nederlandse wielrenners in de Tour de France);

- Gerrie Knetemanlaan (“De Kneet” - wereldkampioen wielrennen 1978 en razend populair, ook vanwege zijn origineel taalgebruik);

- Fanny Blankers-Koenlaan (athlete die in 1948 vier gouden medalilles won op de Olympische Spelen van Londen);

- Rinus Michelslaan (voetbaltrainer en coach van het Nederlandse elftal).

Hierbij hoort allicht de gedachte dat deze beroemdheden de laan geworden straten luister bijzetten en dat omgekeerd bij wijze van waardering hun naam aan een laan gekoppeld wordt. Dat gold hierboven ook voor de Hasseltse lanen met humanistennamen. Vrij recent zijn in de nieuwe Hasseltse wijk Ekkelgaarden zowel een Speculaaslaan (Hasselt noemt zich graag speculaasstad) als een Hassaluthdreef ("hasaluth" betekent hazelarenbos en zou de oorspong van de stadsnaam zijn). En zo komen we bij

\section{6. dreef :}

- dreef : veldweg waarlangs het vee werd gedreven (cfr. laan) Kasteeldreef (Ganshoren / Brussel)

Drève du Château (Braine l'Alleud) vanuit het Brussels binnengedrongen net als bv. blouche $<$ bluts $=$ deuk, drache $<$ drets $=$ regenbui, clinche $<($ deur $)$ klink, blinquer $<$ blinken

\section{7. terras :}

lat. terra $($ aarde $)<$ fr. terrasse $<$

- opgeworpen aarde / aarden wal

- door mensen voor landbouw gemaakt plateau in een heuvelachtig gebied, met als doel regen niet te laten wegvloeien (rijstterrassen op Java)

- buitenzitje op een dak

- plaats buiten een horecazaak waar klanten bij mooi weer iets kunnen gebruiken

- voorgrond op een schilderij

En bij die voorlaatste betekenis, de gezelligste neem ik maar aan, hoort het liedje van Toon Hermans uit 1946, een van zijn vroege jaren : Op een terrasje van het Leidseplein. Is onder die naam makkelijk te vinden op het net en Youtube. De tekst is op zich al een typisch tijdsproduct, met woorden als swingen en okay, die vóór de Tweede Wereldoorlog in onze contreien niemand gebruikte. 
Op 'n zomeravond in augustus

Zat ik met m'n ome Justus

Op 'n terrasje, heel gerust dus

Waar een knul een blonde zus kust

Dat is allemaal heel knus dus

Op 't Leidseplein

Drijf je op de filosofieën

Grote grutten! Mens dan zie je

Jonge paartjes vis-a-vieën (tegenover elkaar zitten)

Bakvissen met blote knieën

Strijkjes spelen melodieën

't Kan gezellig zijn

Als tante zit te theeёn (thee drinken)

Dan geeft oompje gauw een rondje (met bier)

Hij zit te $j$ 'attendraien ("j'attendrai" = Frans voor "ik zal wachten)

Op een flirtje met een blondje

Refrein :

Zo'n zomeravond op het Leidseplein

Dan zie je mensen in de maneschijn

Want om een uur of tien

Kan je er heel wat zien

Op een terrasje van het Leidseplein

Ik zat er in m'n dunne jasje

Met m'n dure hassebasje ("hassebassie", volkstaal voor "borrel")

Op dat mieterse terrasje (oorspronkelijk negatief, later "fijn / aangenaam"

Naast 'n grietje met een tasje

En d'r hondje deed een ...

't Kan gebeuren zeg

Bij een koffie en een zoetje (snoepje uit zoetstof)

Zat ze met d'r leuke snoetje

Hier en daar een zomersproetje

Ze gaf me nonchalant een groetje

Ik likte aan m'n laatste vloetje ("vloeitje" - om sigaretten in te draaien)

En toen ging ze weg

Had ik nog Virginia (Engels sigarettenmerk)

Dan was ze blijven plakken

Maar ' $k$ had alleen nog wat

Eigen teeltjes in mijn zakken (van zelf geteelde tabak)

refrein 
.......jonge gasten

die toevallig ook terrasten

zesendertig cent verbrasten

Ze dronken van die zoetstofkwasten (citroensap met water en suiker)

Ik vond dat het bij hun paste

En ze zeiden vaak okay

Eentje met een foxtrot jas an (Amerikaanse stapdans - modieus jasje)

Daar heb ik de minste last van

Willy Dick weet er geen pas van ( de Amerikaanse zwerversfiguur ?)

... Uden Masman - Cassanova Twee (dirigent jazzband The Ramblers)

En toen begon er eentje met een vrouwenstem te zingen,

Het hele stel ging wiebelen, ze zeiden iets van swingen (jazz-dansen)

Want om een uur of tien

Kan je er heel wat zien

Op een terrasje van het Leidseplein

\section{Bibliografie:}

VAN DER SIJS, N., P.A.F. van VEEN (1997) Etymologisch woordenboek - De herkomst van onze woorden. Utrecht/Antwerpen: Van Dale Lexicografie.

MITZKA, Walther (1960) Etymologisches Wörterbuch. Berlin, Walter De Gruyter

PFEIFER, Wolfgang (1989) Etymologisches Wörterbuch des Deutschen. Berlin, Akademie-Verlag Berlin (3 Bände).

Dictionnaire Le Petit Robert de la langue française, Le Robert (ed.) (2015)

\section{Geciteerd:}

WILMOTS, Jos (2005): Taalknutselboek, Ruys en Daal, Amsterdam

Jos Wilmots, dr. in de letteren, emeritus gewoon hoogleraar Universiteit Hasselt, België;

dr. h. c. Palacký University Olomouc, Czech Republic;

voormalig docent Nederlands aan de Goethe Universität Frankfurt Main - oud-voorzitter

Internationale Vereniging voor Neerlandistiek 
